\title{
Generalised wasting in a young diabetic
}

\author{
A Mohan, R Handa, P Aggarwal, N Wig, V Chaturvedi, A Biswas, J P Wali
}

A 20-year-old man presented to us with complaints of generalised wasting and progressive weight loss. The patient had been diagnosed with diabetes mellitus at the age of 16 years. There was no history of ketosis, although the patient required very high doses of insulin (400-500 units daily). The patient had also noticed abdominal lumps for the last year (figure). Cardiopulmonary examination was normal. The serum chemistry was remarkable for very high triglyceride levels (11.27 $\mathrm{mmol} / \mathrm{l}$, normal $<1.8 \mathrm{mmol} / \mathrm{l}$ ) in addition to elevated blood sugar levels.

\author{
Department of \\ Medicine, All India \\ Institute of Medical \\ Sciences, New Delhi, \\ India \\ A Mohan \\ R Handa \\ P Aggarwal \\ N Wig \\ V Chaturvedi \\ A Biswas \\ J P Wali \\ Correspondence to \\ R Handa \\ Accepted 26 March 1998
}

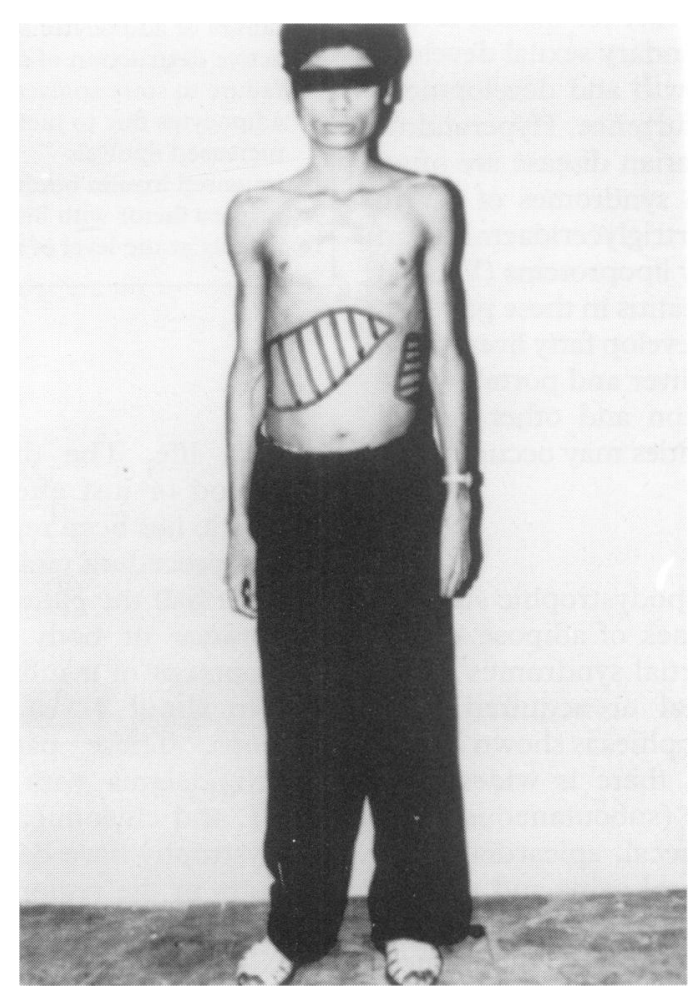

\section{Questions}

1 What does the clinical photograph show?

2 What is the most probable diagnosis?

3 What are the other manifestations of this condition? 
Answers

QUESTION 1

The patient has striking generalised atrophy of the subcutaneous fat. In addition, he has hepatosplenomegaly.

QUESTION 2

In view of the generalised wasting with almost complete absence of adipose tissue in the setting of insulin-resistant diabetes mellitus, the most likely diagnosis is adult-onset acquired generalised lipodystrophy with insulin resistance. Hypertriglyceridaemia and hepatosplenomegaly are characteristic features of this rare condition, which is usually ketosis resistant.

QUESTION 3

The other manifestations include acanthosis nigricans, a cutaneous marker for insulin resistance, and precocious secondary sexual development. The effects on growth and development depend on the age of occurrence. Hyperandrogenism and polycystic ovarian disease are often observed in women with syndromes of severe insulin resistance. Hypertriglyceridaemia and increased very low density lipoproteins (VLDL) may provoke acute pancreatitis in these patients. These patients may also develop fatty liver which may go on to cirrhosis of liver and portal hypertension. Mental retardation and other central nervous system abnormalities may occur.

\section{Discussion}

The cardinal feature of lipodystrophic states is the complete or partial lack of adipose tissue. Both generalised and partial syndromes occur which may be congenital or acquired. The classification of lipodystrophies is shown in box 1. In generalised forms, there is widespread absence of adipose tissue (subcutaneous, perirenal, retroperitoneal, buccal, epicardial, etc). Skeletal muscles, peripheral veins and thyroid appear unusually prominent because of the lack of subcutaneous fat. In partial syndromes, the adipose tissue at unaffected sites may be normal or even hypertrophied. ${ }^{12}$

The acquired syndrome of total lipo-atrophy was first described by Lawrence in $1946 .^{3}$ These patients have a normal distribution of adipose tissue at birth, but develop fat atrophy

\begin{tabular}{|l|}
\hline Lipodystrophic states \\
\hline Generalised lipodystrophy \\
- congenital (Berardinelli-Seip syndrome) \\
acquired (Lawrence syndrome) \\
Partial lipodystrophy \\
- face-sparing (Kobberling-Dunningan syndrome): \\
X-linked dominant, only women are affected \\
(type 1 confined to limbs; type 2 affects trunk \\
also, vulva is spared) \\
cephalothoracic (partial progressive \\
lipodystrophy syndrome) \\
\hline
\end{tabular}

Box 1

\begin{tabular}{|l|}
\hline Proposed pathophysiology of \\
lipodystrophy states \\
\hline failure of adipocytes to develop \\
- active destruction of adipocytes \\
- failure to store triglycerides in existing \\
adipocytes due to ineffective lipogenesis / \\
increased lipolysis \\
- impaired insulin binding to cells \\
- urinary factor with insulin-antagonistic activity \\
\hline
\end{tabular}

Box 2

later in life. The disease has its onset in childhood or just after puberty. The male:female ratio has been reported to be $1: 2 .{ }^{12} \mathrm{~A}$ history of preceding viral illness can be obtained in about half the patients. The generalised disappearance of body fat is followed by the development of insulin-resistant diabetes mellitus in about 4 years time. Ketosis seldom develops. These patients usually manifest hyperlipidaemia with increased triglycerides, VLDL and chylomicrons. Some patients with lipodystrophy have been reported to have had tumours in the region of hypothalamus. ${ }^{4}$ The other clinical features include hepatosplenomegaly, lymphadenopathy, cardiomegaly andhirsutism. Congenital generalised lipodystrophy (Berardinelli-Seip syndrome) is an autosomal recessive disorder. Often, there is a history of parental consanguinity. Generalised absence of adipose tissue is apparent at a very early age. Growth may be accelerated during

\section{Insulin-resistant states}

- prereceptor resistance: mutated insulins or anti-insulin antibodies

- obesity: the commonest cause of insulin resistance

- lipodystrophy syndromes: characterised by fat depletion

- Type A syndrome (absent or dysfunctional receptor): seen in tall young women with hirsutism and polycystic ovaries

- Type B syndrome (insulin receptor antibodies): seen in older women with evidence of immunologic disease (arthralgias, alopecia, parotid enlargement, proteinuria, leucopenia, positive antinuclear antibodies)

- ataxia-telangiectasia: characterised by ataxia, telangiectasia and insulin resistance

- leprechaunism: clinical features include elfin facies, hirsutism, absence of subcutaneous fat and thickened skin

- Rabson-Mendenhall syndrome: comprises dental dysplasia, dystrophic nails, premature puberty and acanthosis nigricans

- Pineal syndrome: characterised by early dentition with malformation of teeth, dry skin, thick nails, sexual precocity

- Alstrom syndrome: characterised by retinal degeneration, nerve deafness, vasopressin-resistant diabetes insipidus, and in males, hypogonadism. Some patients exhibit baldness, hypertriglyceridaemia, hyperuricaemia and aminoaciduria 
the first 4-5 years of life. However, early closure of the epiphyses leads to a reduced final height. Hyperlipidaemia may result in pancreatitis. Polycystic ovarian syndrome with hyperandrogenism and irregular menses has been reported. ${ }^{12}$ The syndromes of partial lipodystrophy include face-sparing lipodystrophy and cephalothoracic lipodystrophy (box 1).

The pathophysiology of these disorders is poorly understood. The currently debated theories are listed in box 2 . The other insulin- resistant states are tabulated in box 3. No therapeutic agent has been shown to be uniformly effective in treating insulin resistance. The diabetic state requires high dosages (sometimes thousands of units per day) of insulin. When very high doses are needed U500 preparations may help cut down the volume of injection. Insulin-sensitizing agents may have a role in the treatment of the

1 Braimon JC, Moller DE. Hereditary and acquired syndromes of severe insulin resistance. In: Pickup J, William G, eds. Textbook of diabetes. Oxford: Blackwell Science, 1997; pp 26.1-15.

2 Flier JS. Syndromes of insulin resistance and mutant insulin. In: de Groot LJ, Besser M, Burger HG, et al, eds, Endocrinology. Philadelphia: WB Saunders Company, 1995; pp 1592-604.

3 Lawrence RD. Lipodystrophy and hepatomegaly with diabetes, lipidaemia, and other metabolic disturbances. A case throwing new light on the action of insulin. A case 1946;1:724.

4 Seip M. Lipodystrophy and gigantism with associated endo-

Seip M. Lipodystrophy and gigantism with associated endo-
crine manifestations: a new diencephalic syndrome? Acta crine manifestations: a n
Paediatr 1959;48:555-74. severe insulin resistance states. Metformin and thiazolidinedione have been tried with variable results in some patients with Type $B$ insulin resistance syndrome. ${ }^{5}$ Insulin-like growth factor-1, a member of the proinsulin family, also seems to hold promise in the treatment of severe insulin-resistant states. ${ }^{6}$ Topical application of tretinoin cream or gel has been found to be useful in controlling acanthosis nigricans. ${ }^{7}$ Virilisation features may require spironolactone, or low-dose cyproterone or oral contraceptive pills.

\section{Final diagnosis}

Adult-onset acquired generalised lipodystrophy with insulin resistance.

Keywords: lipodystrophy syndromes; wasting; diabetes mellitus

$5 \mathrm{Di}$ Paolo S. Metformin ameliorates extreme insulin resistance in a patient with anti-insulin receptor antibodies: description of insulin receptor and post receptor effects in vivo and in vitro. Acta Endocrinol 1992;126:1473-90.

6 Morrow LA, O'Brien MB, Moller DE, Flier JS, Moses AC. Recombinant human insulin-like growth factor-I therapy improves glycemic control and insulin action in the Type A syndrome of insulin resistance. $\mathcal{f}$ Clin Endocrinol Metab 1994;79:205-10.

7 Moses AC, Abrahamson MJ. Therapeutic approaches to insulin resistance. In: Moller $\mathrm{DE}$, ed. Insulin resistance. Chichester: John Wiley and Sons, 1993; pp 385-410.

\title{
Orthostatic hypotension in an elderly patient
}

\author{
L Allcock, C Polack, D O'Shea, P McKenna, D O'Shea
}

\section{Department of Medicine, North Tyneside Health Care NHS Trust, North Tyneside General Hospital, North Shields, Tyne \& Wear NE29 8NH, UK \\ L Allcock \\ C Polack \\ D O'Shea \\ P McKenna}

\section{Department of Endocrinology, Charing Cross Hospital, Hammersmith Hospitals NHS Trust, London W6 8RF, UK D O'Shea}

Correspondence to Dr D O'Shea, Department of Medicine, Royal Victoria Infirmary c/o Ward 15 Offices, Queen Victoria Road, Newcastle Upon-Tyne, NE1 4LP, UK
An 81-year-old woman was admitted following a collapse. She described feeling progressively dizzy and faint for several weeks prior to admission. Five years previously she had undergone oophorectomy and pelvic clearance for ovarian carcinoma. She had a history of hypertension and ischaemic heart disease. Medications on admission were: isosorbide mononitrate $10 \mathrm{mg}$ bid, methotrimeprazine $25 \mathrm{mg}$ bid, fluoxetine $20 \mathrm{mg}$ od, amitriptyline $50 \mathrm{mg}$ nocte, aspirin $150 \mathrm{mg}$ od, amiodarone $100 \mathrm{mg}$ od, frusemide $80 \mathrm{mg}$ od, and megestrol $160 \mathrm{mg}$ od.

Examination was unremarkable other than an orthostatic drop in blood pressure from 113/69 $\mathrm{mmHg}$ lying to $83 / 50 \mathrm{mmHg}$ on standing with postural-related dizziness. Her full blood count, electrolytes, urea, creatinine and glucose were all normal. A baseline cortisol $(09.00 \mathrm{~h})$ was $<50$ $\mathrm{nmol} / \mathrm{l}$, with an adrenocorticotropin (ACTH) level of $16 \mathrm{ng} / \mathrm{l}$ (reference range < 47). A short synacthen test confirmed adrenal insufficiency with a baseline cortisol of $<50 \mathrm{nmol} / 1$ and a peak of $220 \mathrm{nmol} / 1$ at 30 minutes. Pituitary hormone profile showed gonadotropin levels to be suppressed with luteinising hormone $0.1 \mathrm{IU} / 1$, and follicle-stimulating hormone $0.7 \mathrm{IU} / 1$, while her prolactin was $220 \mathrm{mU} / 1$ (60-600). Thyroid function tests showed a free thyroxine of $16.8 \mathrm{pmol} / 1(9.8-23.1)$ and a thyroid-stimulating hormone of $2.6 \mathrm{mU} / 1(0.35-5.5)$. An autoantibody screen was negative. CA-125 levels of $7 \mathrm{kU} / 1(0-35)$ and $17 \beta-\mathrm{OH}$-oestradiol below the working range of the assay suggested that she did not have recurrence of an oestrogen-secreting, epithelial ovarian carcinoma. Computed tomography (CT) scan of the brain and pituitary was normal and a CT scan of the abdomen and pelvis demonstrated normal adrenal glands, with no evidence of recurrence of the ovarian tumour.

\section{Questions}

1 What are the potential causes of this patient's orthostatic hypotension?

2 What is the most likely cause of her impaired hypothalamic-pituitary-adrenal (HPA) function? 3 What treatment would you advise for her orthostatic hypotension? 